\title{
Chiral Phosphoric Acid Promoted Chiral 1H NMR Analysis of Atropisomeric Quinolines
}

\author{
Junlin Wan, Jun Jiang and Juan $L i$ * \\ College of Chemistry and Materials Engineering, Wenzhou University, Wenzhou, China
}

An efficient enantioselective NMR analysis of atropisomeric quinolines in the promotion of chiral phosphoric acid is described, in which a variety of racemic 4-aryl quinolines were well-recognized with up to $0.17 \mathrm{ppm} \Delta \Delta \delta$ value. Additionally, the optical purities of different nonracemic substrates could be evaluated fast via NMR analysis with high accuracy.

Keywords: chiral recognition, 1H NMR analysis, quinolines, chiral phosphoric acid, chiral shift reagents

\section{INTRODUCTION}

Axial chirality is one of the important types of molecular asymmetry created from restriction of carbon-carbon or carbon-nitrogen single-bond rotation. Since Christie and Kenner reported the first detection of atropisomerism in 1922 (Christie and Kenner, 1922), axial chirality was found in a

OPEN ACCESS

Edited by:

Toshifumi Dohi,

Ritsumeikan University, Japan

Reviewed by:

Keiji Mori,

Tokyo University of Agriculture and

Technology, Japan

Ravi Kumar,

J. C. Bose University of Science and

Technology, YMCA, India

*Correspondence:

Juan $L i$

juanli@wzu.edu.cn

Specialty section:

This article was submitted to

Analytical Chemistry,

a section of the journal

Frontiers in Chemistry

Received: 26 February 2021

Accepted: 27 April 2021

Published: 10 June 2021

Citation:

Wan J, Jiang J and Li J (2021) Chiral Phosphoric Acid Promoted Chiral 1H NMR Analysis of

Atropisomeric Quinolines.

Front. Chem. 9:672704.

doi: $10.3389 /$ fchem.2021.672704 lot of natural products and pharmaceutical compounds as exemplified by michellamines (Manfredi et al., 1991; Bringmann et al., 1993) and vancomycin(Nicolaou et al., 1999). Besides, many chiral ligands and catalysts, such as BINOL, BINAP, and phosphoric acids, have been developed based on axially chiral biaryl scaffolds(Miyashita et al., 1980; Akutagawa, 1995; Kumobayashi et al., 2001; Brunel, 2005; Brunel, 2007; Genet et al., 2014). It is well-known that the enantiopurities of chiral ligands and catalysts are critical to their enantiocontrol, and atropisomers of bioactive molecules always exhibit different pharmacodynamic and pharmacokinetic behavior both in vivo and in vitro (Eichelbaum and Gross, 1996; Clayden et al., 2009). Thus, the development of efficient methods to recognize and determine atropisomeric compounds becomes an interesting target and is always in high demand. As key analysis methods, GC (Schurig and Nowotny, 1990), IR (Reetz et al., 1998), HPLC (Han, 1997), circular dichroism (Ding et al., 1999; Nieto et al., 2008; Ghosn and Wolf, 2009; Nieto et al., 2010), fluorescence spectroscopy (James et al., 1995; Mei and Wolf, 2004; Pu, 2004; Zhao et al., 2004; Tumambac and Wolf, 2005; Liu et al., 2009), electrophoresis technologies (Reetz et al., 2000), and NMR spectroscopy have been efficiently employed in chiral determinations. Among these classic technologies, NMR analysis affords an ideal platform to explore efficient chiral analysis strategies because of its mild condition, easy operation, fast evaluation, high sample tolerance, etc. Over the past few decades, a lot of chiral shift reagents (CSRs) (Frazer et al., 1971; Goering et al., 1971; Yeh et al., 1986; Ghosh et al., 2004; Yang et al., 2005; Mori et al., 2013) or chiral solvating reagents (CSAs) (Pirkle, 1966; Lancelot et al., 1969; Parker, 1991; Wenzel and Wilcox, 2003; Seco et al., 2004; Lovely and Wenzel, 2006; Ema et al., 2007; Wenzel, 2007; Iwaniuk and Wolf, 2010; Moon et al., 2010; Gualandi et al., 2011; Pham and Wenzel, 2011; Quinn et al., 2011; Wenzel and Chisholm, 2011; Ma et al., 2012; Labuta et al., 2013; Zhou et al., 2015; Bian et al., 2016a; Akdeniz et al., 2016; Bian et al., 2016b; Huang et al., 2016) were successfully designed and employed in chiral NMR analysis. Encouraged by these achievements and our continuous efforts to study chiral interactions, we were particularly interested in exploring a novel NMR-based chiral analysis method for our synthetic targets: In 2017, we reported an enantioselective NMR analysis of indoloquinazoline alkaloid-type tertiary alcohols with chiral phosphoric acid (CPA) (Akiyama et al., 2006; Akiyama, 2007; Akiyama 


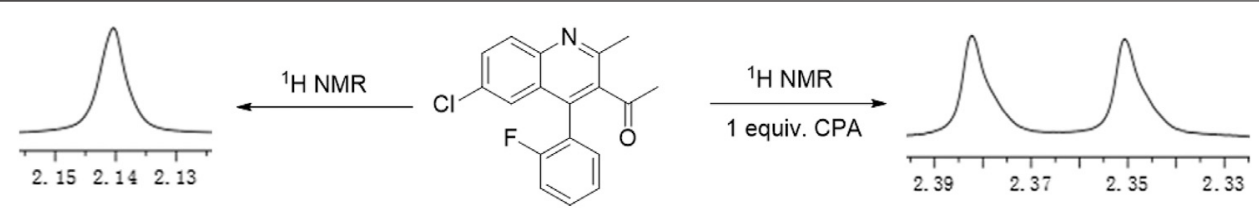

FIGURE 1 | Chiral 1H NMR analysis of aryl quinolines with a chiral phosphoric acid.

TABLE 1 | Evaluating the chiral recognition abilities of chiral phosphoric acids (R)-C with 1a. ${ }^{a}$<smiles>CC(=O)c1c(C)nc2ccc(Cl)cc2c1-c1c(F)cccc1[18O]c1c([Al])cc2ccccc2c1OP(=O)(O)Oc1c([Al])cc2ccccc2c1-c1ccccc1</smiles>

(R)-C1: $\mathrm{Ar}=1$-naphthyl

(R)-C2: $\mathrm{Ar}=2,4,6$-trimethylphenyl

(R)-C3: $\mathrm{Ar}=1$-pyrenyl

(R)-C4: $\mathrm{Ar}=4$-2-naphthalenyl)phenyl

(R)-C5: $\mathrm{Ar}=2,4,6$-triisopropylphenyl

(R)-C6: $\mathrm{Ar}=$ triphenylsilyl

(R)-C7: $\mathrm{Ar}=$ phenyl

\section{Entry}

\section{$x$ equiv. of phosphoric acid}

deuterated solvents<smiles>O=P(O)(Oc1ccccc1)Oc1c(Br)cc2c(c1-c1c(Br)cc3c(c1Br)CCCC3)CCCC2</smiles>

(R)-C8: $\mathrm{Ar}=1$-naphthyl
NMR analysis<smiles></smiles>

(R)-C9: Ar = 1-naphthyl $\frac{\text { Chiral shift }}{\text { Reagent }}$
(R)-C1
(R)-C2
(R)-C3
(R)-C4
(R)-C5
(R)-C6
(R)-C7
(R)-C8
(R)-C9
(R)-C1
(R)-C1
(R)-C1
(R)-C1
(R)-C1
(R)-C1
(R)-C1
(R)-C1
(R)-C1

\begin{tabular}{c} 
Deuterated \\
\hline Solvents \\
$\mathrm{CD}_{3} \mathrm{OD}$ \\
$\mathrm{CD}_{3} \mathrm{OD}$ \\
$\mathrm{CD}_{3} \mathrm{OD}$ \\
$\mathrm{CD}_{3} \mathrm{OD}$ \\
$\mathrm{CD}_{3} \mathrm{OD}$ \\
$\mathrm{CD}_{3} \mathrm{OD}$ \\
$\mathrm{CD}_{3} \mathrm{OD}$ \\
$\mathrm{CD}_{3} \mathrm{OD}$ \\
$\mathrm{CD}_{3} \mathrm{OD}$ \\
$\mathrm{CDCl}_{3}$ \\
$\mathrm{DMSO} \mathrm{D}$ \\
$\mathrm{DMF}_{6}-\mathrm{D}_{7}$ \\
$\mathrm{Acetone}-\mathrm{D}_{6}$ \\
$\mathrm{CD}_{3} \mathrm{CN}$ \\
$\mathrm{C}_{6} \mathrm{D}_{6}$ \\
$\mathrm{CD}_{3} \mathrm{OD}$ \\
$\mathrm{CD}_{3} \mathrm{OD}$ \\
$\mathrm{CD}_{3} \mathrm{OD}$
\end{tabular}

$\Delta \Delta \delta(\mathrm{ppm})$ 0.03 0.01

0

0

0

0

0.02

0.01

nd

0

0.02

0.01

0.1

0.03

0.02

0.05

aUnless otherwise noted, all samples were prepared by mixing $(R)-\mathrm{C}(0.01 \mathrm{mmol})$ and the guests $2 \mathrm{a}(0.01 \mathrm{mmol})$ in $\mathrm{CD}_{3} \mathrm{OD}(0.5 \mathrm{ml})$ at $25^{\circ} \mathrm{C}$.

${ }^{b} 0.1 \mathrm{ml} \mathrm{CDCl} 3$ was added.

${ }^{\circ} 0.5$ equiv. of (R)-C1 was used.

$d_{2}$ equiv. of (R)-C1 was used. 
TABLE 2 | Measurements of $1 \mathrm{H}$ chemical shift nonequivalences (DDd) of racemic aryl quinolinones. ${ }^{a}$

\section{Entry}

$1^{b}$

\section{Aryl quinolinone}

Spectra
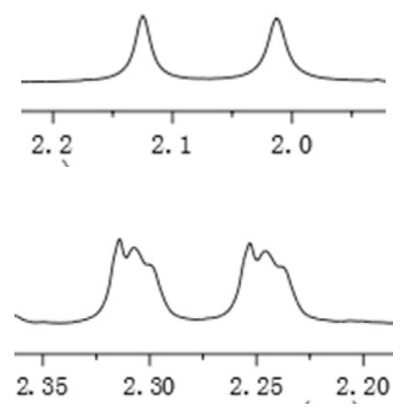

$3^{b}$<smiles>CC(=O)c1c(C)nc2ccc([N+](=O)[O-])cc2c1-c1ccccc1F</smiles><smiles>CC(=O)c1c(C)nc2cc(Cl)ccc2c1-c1ccccc1C(C)C</smiles><smiles>CC(=O)c1c(C)nc2ccc([N+](=O)[O-])cc2c1-c1ccccc1Cl</smiles>

4

$5^{\mathrm{b}}$<smiles>CCCc1ccccc1-c1c(C(C)=O)c(C)nc2cc(Cl)ccc12</smiles>

$6^{b}$

7<smiles>CC(=O)c1c(C)nc2ccccc2c1-c1ccccc1Br</smiles><smiles>CC(=O)c1c(C)nc2ccccc2c1-c1ccccc1</smiles><smiles>CC(=O)c1c(C)nc2ccccc2c1-c1cccc2ccccc12</smiles>

$8^{\mathrm{c}}$

9<smiles>CC(=O)c1c(C)nc2ccccc2c1-c1ccccc1C</smiles><smiles>CC(=O)c1c(C)nc2ccccc2c1-c1ccccc1I</smiles>

$\Delta \Delta \delta(\mathrm{ppm})$
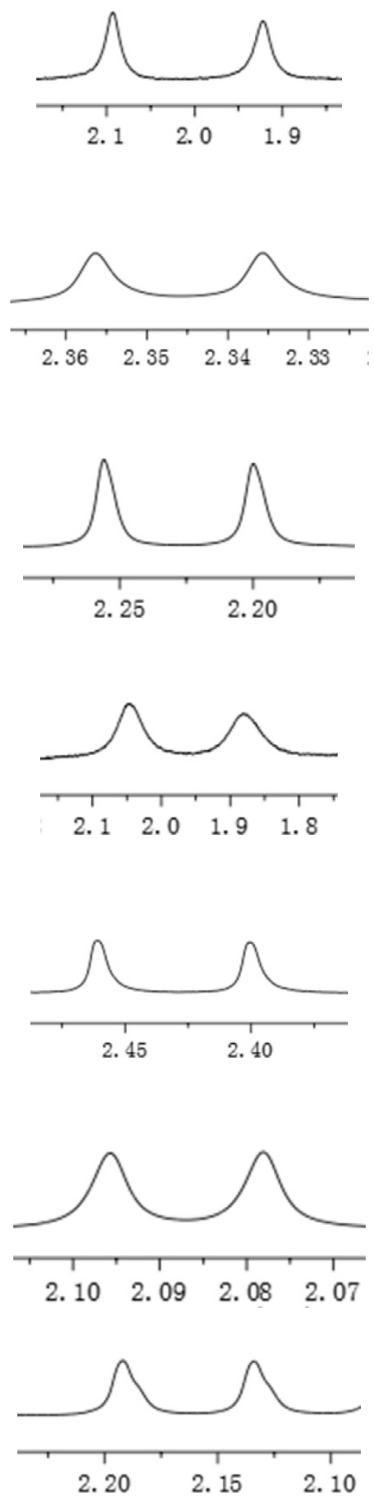

0.17

0.02

0.06

0.17

0.02

0.11

0.06

0.07 
TABLE 2 | (Continued) Measurements of $1 \mathrm{H}$ chemical shift nonequivalences (DDd) of racemic aryl quinolinones. ${ }^{\mathrm{a}}$

\section{Entry}

10<smiles>COC(=O)c1ccccc1-c1c(C(C)=O)c(C)nc2ccccc12</smiles>

$11^{\mathrm{b}}$<smiles>COc1ccccc1-c1c(C(C)=O)c(C)nc2ccccc12</smiles>

12

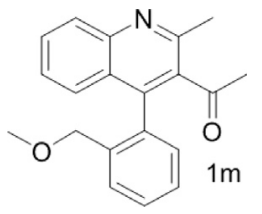

13<smiles>COCCc1ccccc1-c1c(C(C)=O)c(C)nc2ccccc12</smiles>

14<smiles>CC(=O)c1c(C)nc2ccccc2c1-c1ccccc1CO[N+]#N</smiles>

15

16<smiles>CC(=O)c1c(C)nc2ccccc2c1-c1ccccc1COc1ccc(C(C)(C)C)cc1</smiles><smiles>CCOC(=O)c1c(C)nc2ccc(Cl)cc2c1-c1ccccc1F</smiles>

17<smiles>COC(=O)c1c(C)nc2ccc(Cl)cc2c1-c1ccccc1F</smiles>

Spectra

$\Delta \Delta \delta(p p m)$
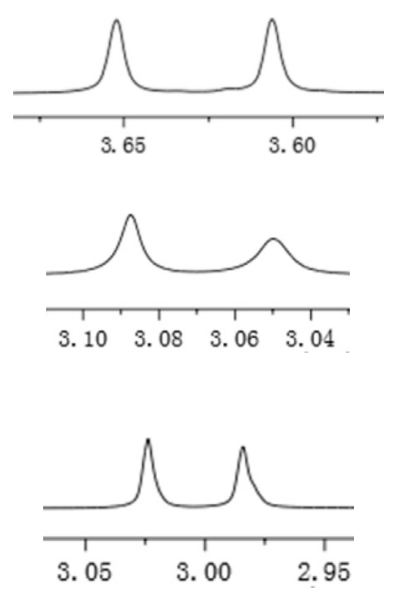

0.04

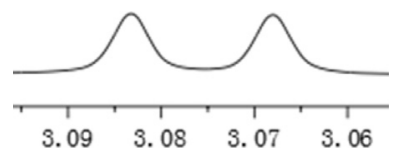

0.01

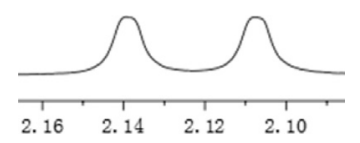

0.03
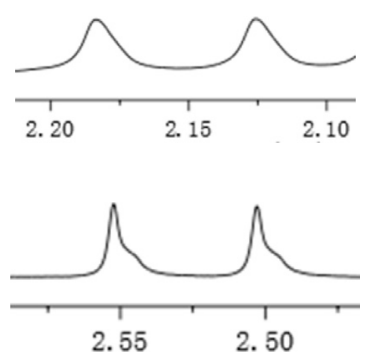

0.05

0.06

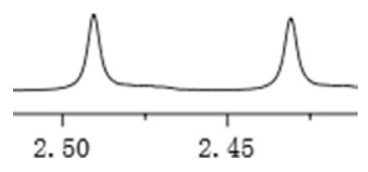

(Continued on following page) 
TABLE 2 | (Continued) Measurements of $1 \mathrm{H}$ chemical shift nonequivalences (DDd) of racemic aryl quinolinones. ${ }^{a}$

Entry Aryl quinolinone Spectra

a Unless otherwise noted, all samples were prepared by mixing (R)-C1 (0.01 mmol) and the guests 2 (0.01 $\mathrm{mmol}$ in $C D_{3} \mathrm{OD}(0.5 \mathrm{ml})$ and $C D C l_{3}(0.1 \mathrm{ml})$ at $25^{\circ} \mathrm{C}$.

${ }^{b} 0.5 \mathrm{ml} \mathrm{C}_{6} D_{6}$ was used.

${ }^{c} 2$ equiv. of (R)-C1 was used.

and Mori, 2015) promotion, in which a fast reaction condition optimization of amino acid metal salt-catalyzed asymmetric aldol reaction was also achieved (Liu et al., 2017); besides, a variety of racemic 4-aryl quinazolinones, such as afloqualone and IC87114, were also well-recognized, and the optical purities of different nonracemic substrates could be evaluated fast with high accuracy (Wu et al., 2018). Encouraged by these results and our recent research on the catalytic asymmetric construction of atropisomeric quinolines, we wish to report an efficient chiral recognition of quinoline atropisomers by chiral phosphoric acid: In the presence of 1 equivalent of $\alpha$-naphthyl phosphoric acid, a variety of racemic quinolines were well-recognized with up to $0.17 \mathrm{ppm} \Delta \Delta \delta$ value; additionally, the corresponding analysis system can also be employed in the accurate determination of enantioselectivities of axial chiral quinolines.

\section{RESULTS AND DISCUSSION}

As shown in Figure 1, the methyl peak on the benzyl position of racemic 1-(6-chloro-4-(2-fluorophenyl)-2-methylquinolin-3-yl) ethan-1-one 1a is unimodal on $1 \mathrm{H}$ NMR spectrum in the

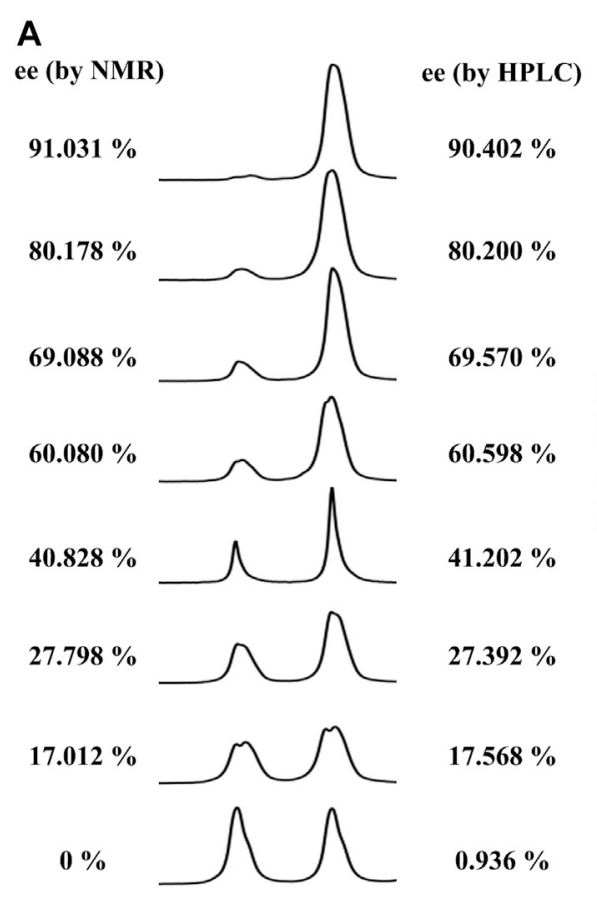

B

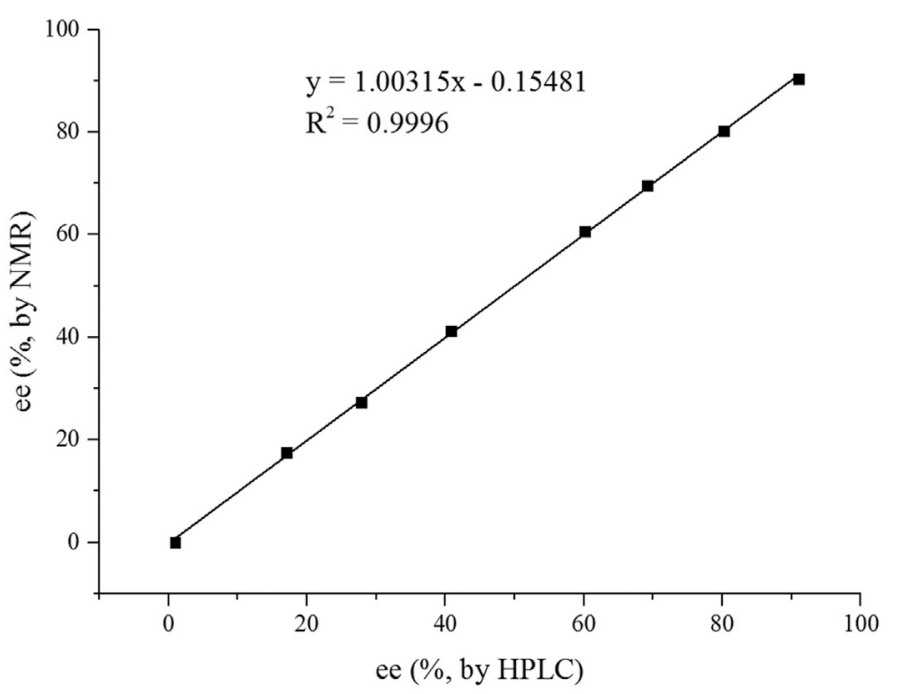

FIGURE 2 | (A) Selected regions of the $1 \mathrm{H}$ NMR spectra of nonracemic aryl quinolinone samples (varied ee values) with (R)- $\mathrm{C} 1 \mathrm{in} 0.5 \mathrm{ml} \mathrm{CD}_{3} \mathrm{OD}$ and $0.1 \mathrm{ml} \mathrm{CDCl}$; (B) linear correlation between ee values determined by HPLC and NMR ee values, $R^{2}=$ correlation coefficient. 
absence of chiral phosphoric acid. Generally, the addition of 1 equivalent of chiral phosphoric acid brought obvious chemical shift nonequivalences of this methyl peak of 1a, suggesting the strong chiral interaction between chiral phosphoric acids and 4aryl quinoline. It was shown that the substituents on phosphoric acids had obvious influence on the recognition. For example, 3,3'a-naphthyl-substituted phosphoric acid C1 afforded a baseline resolution and the largest chemical shift nonequivalence $(\Delta \Delta \delta=0.03)$ of a methyl $\mathrm{H}$ signal of $\mathbf{1 a}$ in $\mathrm{CD}_{3} \mathrm{OD}$ at $25^{\circ} \mathrm{C}$, while 3,3'-phenyl-substituted phosphoric acid $\mathrm{C} 7$ failed to differentiate atropisomers of 1a. Besides, deuterated solvents also played an important role in chiral recognition. As shown in Table 1, chemical shift nonequivalence of methyl $\mathrm{H}$ of 1a's atropisomers was observed when $\mathrm{CPA} \mathbf{C 1}$ and 1 a were combined in $\mathrm{CD}_{2} \mathrm{Cl}_{2}$, acetone-D6, $\mathrm{CD}_{3} \mathrm{CN}$, and $\mathrm{C}_{6} \mathrm{D}_{6}$, while highly polar solvent, such as DMF-D7 and DMSO-D6, seemed to break the interaction between the chiral sensor and analyte, resulting in no differentiation of atropisomers. Besides, different peaks overlapped together when $\mathrm{CDCl}_{3}$ was employed as solvent. Significantly, $\mathrm{C}_{6} \mathrm{D}_{6}$ enabled the best chiral recognition of up to $\Delta \Delta \delta 0.1 \mathrm{ppm}$, albeit with poor solubility of CPA and quinoline analytes. Considering the fact that $\mathrm{CPA}$ and quinoline mixture dissolve well in $\mathrm{CDCl}_{3}$, binary solvents of $\mathrm{CD}_{3} \mathrm{OD}$ and $\mathrm{CDCl}_{3}$ (5/1) were chosen as analysis media in the purpose of balancing solubility and recognition, offering eminent solubility and baseline resolution (entry 16). Additionally, the amount of 1a also influenced differentiation; for example, baseline resolution was not achieved when a 0.5 equivalent of chiral phosphoric acid $\mathrm{C} 1$ was used, while increasing the amount of $\mathrm{C} 1$ to 2 equivalent resulted in larger chemical shift nonequivalence $(\Delta \Delta \delta=0.05)$. Finally, under the balance of atom economy and recognition, 1 equivalent of (R)-C1 was employed as a chiral sensor (entry 17).

Under optimized conditions, a series of 4-aryl quinoline guests were tested. First, the influence of substituents on quinoline (ring 1) was evaluated. It was shown that different electronwithdrawing groups on ring 1 were fit well under standard conditions, providing baseline resolutions and $0.02-0.17 \mathrm{ppm}$ $\Delta \Delta \delta$ values, respectively (Table 2 , entries 1-5). Besides, different R3 groups on quinoline such as acetyl, ethyl formate, methyl formate and trifluoroacetyl were also tested, all of which led to clear recognition of atropisomers with up to $0.07 \mathrm{ppm} \Delta \Delta \delta$ values. Subsequently, different 4 -aryl groups (ring 2) were also studied. As shown in Table 2, a variety of electron-withdrawing or electron-donating groups on ring 2 were well-tolerated, and substituents with either moderate or bulky size on the 2'-position of ring 2 all resulted in clear baseline resolution with good chemical shift nonequivalences. Noticeably, when 1-\{4-[(1,1'biphenyl)-2-yl]-2-methylquinolin-3-yl\} ethan-1-one $\mathbf{1 g}$ was employed as analyte, the largest chemical shift nonequivalence of $0.17 \mathrm{ppm} \Delta \Delta \delta$ was obtained. Interestingly, when $\mathbf{1 k - 1 n}$ were employed as guests, obvious split peaks on $\alpha-\mathrm{H}$ of oxygen were observed. It is also worth noting that nitro-substituted substrates $\mathbf{1 b}$ and $\mathbf{1 g}$ also afforded good differentiation results (chemical shift nonequivalence of 0.11 and $0.17 \mathrm{ppm} \Delta \Delta \delta$, respectively), possibly due to the steric hindrance effect of nitro group.

With this optimal recognition condition, the possibility of our methodology in the enantiomeric determination of various nonracemic $\mathbf{1 j}$ samples was explored. As shown in Figure 2, 1j samples with different enantiopurities was combined with 1 equivalent of CPA $\mathrm{C} 1$ and then monitored by NMR. It was revealed that the optical purities of 2 a could be accurately obtained by integrating the corresponding $\mathrm{H}$ signals of the methyl group of $\mathbf{1 j}$, which were very close to the exact results measured by HPLC. Compared with those data obtained from chiral HPLC analysis, an excellent linear relationship of a correlation coefficient $R^{2} 0.9996$ and up to $0.03 \%$ absolute error was obtained.

\section{CONCLUSION}

In conclusion, an efficient phosphoric acid-promoted chiral recognition of atropisomeric quinolines via NMR analysis was successfully developed. With this method, atropisomers of various quinolines were well-discriminated with base resolution; besides, the optical purities of different nonracemic quinoline $\mathbf{1 j}$ could be evaluated fast with high accuracy. This method broadens the chiral analysis ability of chiral phosphoric acids, which encourages us to further explore the interaction of chiral acids with different analytes.

\section{DATA AVAILABILITY STATEMENT}

The original contributions presented in the study are included in the article/Supplementary Material, further inquiries can be directed to the corresponding author.

\section{AUTHOR CONTRIBUTIONS}

All authors listed have made a substantial, direct and intellectual contribution to the work, and approved it for publication.

\section{FUNDING}

This research was financially supported by Major Research Plan of Wenzhou City (No. ZG2017027).

\section{SUPPLEMENTARY MATERIAL}

The Supplementary Material for this article can be found online at: https://www.frontiersin.org/articles/10.3389/fchem.2021.672704/ full\#supplementary-material 


\section{REFERENCES}

Akdeniz, A., Minami, T., Watanabe, S., Yokoyama, M., Ema, T., and Anzenbacher, P. (2016). Determination of Enantiomeric Excess of Carboxylates by Fluorescent Macrocyclic Sensors. Chem. Sci. 7, 2016-2022. doi:10.1039/ C5SC04235F

Akiyama, T., and Mori, K. (2015). Stronger Brønsted Acids: Recent Progress. Chem. Rev. 115, 9277-9306. doi:10.1021/acs.chemrev.5b00041

Akiyama, T., Itoh, J., and Fuchibe, K. (2006). Recent Progress in Chiral Brønsted Acid Catalysis. Adv. Synth. Catal. 348, 999-1010. 10.1002/adsc.200606074

Akiyama, T. (2007). Stronger Brønsted Acids. Chem. Rev. 107, 5744-5758. doi:10. $1021 / \mathrm{cr} 068374 \mathrm{j}$

Akutagawa, S. (1995). Asymmetric Synthesis by Metal BINAP Catalysts. Appl. Catal. A: Gen. 128, 171-207. doi:10.1016/0926-860X(95)00097-6

Bian, G., Yang, S., Huang, H., Zong, H., and Song, L. (2016a). A Bisthiourea-Based $1 \mathrm{H}$ NMR Chiral Sensor for Chiral Discrimination of a Variety of Chiral Compounds. Sensors Actuators B: Chem. 231, 129-134. doi:10.1016/j.snb.2016. 03.002

Bian, G., Yang, S., Huang, H., Zong, H., Song, L., Fan, H., et al. (2016b). Chirality Sensing of Tertiary Alcohols by a Novel strong Hydrogen-Bonding Donor Selenourea. Chem. Sci. 7, 932-938. doi:10.1039/C5SC03780H

Bringmann, G., Zagst, R., Schäffer, M., Hallock, Y. F., Cardellina, J. H., and Boyd, M. R. (1993). The Absolute Configuration of Michellamine B, a "Dimeric", AntiHIV-active Naphthylisoquinoline Alkaloid. Angew. Chem. Int. Ed. Engl. 32, 1190-1191. doi:10.1002/anie.199311901

Brunel, J. M. (2005). BINOL: a Versatile Chiral Reagent. Chem. Rev. 105, 857-898. doi:10.1021/cr040079g

Brunel, J. M. (2007). Update 1 of: BINOL: a Versatile Chiral Reagent. Chem. Rev. 107, PR1-PR45. doi:10.1021/cr078004a

Christie, G. H., and Kenner, J. (1922). LXXI.-The Molecular Configurations of Polynuclear Aromatic Compounds. Part I. The Resolution of $\gamma-6: 6^{\prime}$-dinitroand $4: 6: 4^{\prime}: 6^{\prime}$-Tetranitro-Diphenic Acids into Optically Active Components. J. Chem. Soc. Trans. 121, 614-620. doi:10.1039/CT9222100614

Clayden, J., Moran, W. J., Edwards, P. J., and LaPlante, S. R. (2009). The challenge of Atropisomerism in Drug Discovery. Angew. Chem. Int. Ed. 48, 6398-6401. doi:10.1002/anie.200901719

Ding, K., Ishii, A., and Mikami, K. (1999). Super High Throughput Screening (SHTS) of Chiral Ligands and Activators: Asymmetric Activation of Chiral Diol-Zinc Catalysts by Chiral Nitrogen Activators for the Enantioselective Addition of Diethylzinc to Aldehydes. Angew. Chem. Int. Ed. 38, 497-501. doi:10.1002/(sici) 1521-3773(19990215)38:4<497:aid-anie497>3.0.co;2-g

Eichelbaum, M., and Gross, A. S.(1996). Stereochemical Aspects of Drug Action and Disposition. Adv. Drug Res. 28, 1-64. doi:10.1016/S0065-2490(96) 80003-7

Ema, T., Tanida, D., and Sakai, T. (2007). Versatile and Practical Macrocyclic Reagent with Multiple Hydrogen-Bonding Sites for Chiral Discrimination in NMR. J. Am. Chem. Soc. 129, 10591-10596. doi:10.1021/ja073476s

Frazer, R. R., Petit, M. A., and Saunders, J. K. (1971). Determination of Enantiomeric Purity by an Optically Active Nuclear Magnetic Resonance Shift Reagent of Wide Applicability. J. Chem. Soc. Chem. Commun., 1971, 1450-1451. doi:10.1039/c29710001450

Genet, J.-P., Ayad, T., and Ratovelomanana-Vidal, V. (2014). Electron-deficient Diphosphines: the Impact of DIFLUORPHOS in Asymmetric Catalysis. Chem. Rev. 114, 2824-2880. doi:10.1021/cr4003243

Ghosh, I., Zeng, H., and Kishi, Y. (2004). Application of Chiral Lanthanide Shift Reagents for Assignment of Absolute Configuration of Alcohols. Org. Lett. 6, 4715-4718. doi:10.1021/ol048061f

Ghosn, M. W., and Wolf, C. (2009). Chiral Amplification with a Stereodynamic Triaryl Probe: Assignment of the Absolute Configuration and Enantiomeric Excess of Amino Alcohols. J. Am. Chem. Soc. 131, 16360-16361. doi:10.1021/ ja907741v

Goering, H. L., Eikenberry, J. N., and Koermer, G. S. (1971). Tris[3(trifluoromethylhydroxymethylene)-d-camphorato]Europium(III). Chiral Shift Reagent for Direct Determination of Enantiomeric Compositions. J. Am. Chem. Soc. 93, 5913-5914. doi:10.1021/ja00751a065
Gualandi, A., Grilli, S., Savoia, D., Kwit, M., and Gawroński, J. (2011) C-hexaphenyl-substituted Trianglamine as a Chiral Solvating Agent for Carboxylic Acids. Org. Biomol. Chem. 9, 4234-4241. doi:10.1039/c0ob01192d

Han, S. M. (1997). Direct Enantiomeric Separations by High Performance Liquid Chromatography Using Cyclodextrins. Biomed. Chromatogr. 11, 259-271. doi:10.1002/(sici)1099-0801(199709)11:5<259:aid-bmc701>3.0.co;2-u

Huang, H., Bian, G., Zong, H., Wang, Y., Yang, S., Yue, H., et al. (2016). Chiral Sensor for Enantiodiscrimination of Varied Acids. Org. Lett. 18, 2524-2527. doi:10.1021/acs.orglett.6b00088

Iwaniuk, D. P., and Wolf, C. (2010). A Versatile and Practical Solvating Agent for Enantioselective Recognition and NMR Analysis of Protected Amines. J. Org. Chem. 75, 6724-6727. doi:10.1021/jo101426a

James, T. D., Samankumara Sandanayake, K. R. A., and Shinkai, S. (1995). Chiral Discrimination of Monosaccharides Using a Fluorescent Molecular Sensor. Nature 374, 345-347. doi:10.1038/374345a0

Kumobayashi, H., Miura, T., Sayo, N., Saito, T., and Zhang, X. (2001). Recent Advances of BINAP Chemistry in the Industrial Aspects. Synlett 2001 (Special Issue), 1055-1064. doi:10.1055/s-2001-14625

Labuta, J., Ishihara, S., Šikorský, T., Futera, Z., Shundo, A., Hanyková, L., et al. (2013). NMR Spectroscopic Detection of Chirality and Enantiopurity in Referenced Systems without Formation of Diastereomers. Nat. Commun. 4, 2188. doi: $10.1038 /$ ncomms3188

Lancelot, C. J., Harper, J. J., and Schleyer, P. v. R. (1969). Participation by Neighboring Aryl Groups. II. Accurate Determinations of Inductive and Anchimeric Assistance Effects by a Hammett-Taft Correlation. J. Am. Chem. Soc. 91, 4294-4296. doi:10.1021/ja01043a051

Liu, H.-L., Hou, X.-L., and Pu, L. (2009). Enantioselective Precipitation and SolidState Fluorescence Enhancement in the Recognition of a-Hydroxycarboxylic Acids. Angew. Chem. Int. Ed. 48, 382-385. doi:10.1002/anie.200804538

Liu, C.-X., Zheng, L., Zhu, L., Xiao, H.-P., Li, X., and Jiang, J. (2017). Efficient Chiral $1 \mathrm{H}$ NMR Analysis of Indoloquinazoline Alkaloids Phaitanthrin A, Cephalanthrin-A and Their Analogues with a Chiral Phosphoric Acid. Org. Biomol. Chem. 15, 4314-4319. doi:10.1039/C7OB00823F

Lovely, A. E., and Wenzel, T. J. (2006). Chiral NMR Discrimination of Secondary Amines Using (18-Crown-6)-2,3,11,12-tetracarboxylic Acid. Org. Lett. 8, 2823-2826. doi:10.1021/ol0609558

Ma, Q., Ma, M., Tian, H., Ye, X., Xiao, H., Chen, L.-h., et al. (2012). A Novel Amine Receptor Based on the Binol Scaffold Functions as a Highly Effective Chiral Shift Reagent for Carboxylic Acids. Org. Lett. 14, 5813-5815. doi:10.1021/ ol3027686

Manfredi, K. P., Blunt, J. W., Cardellina, J. H., McMahon, J. B., Pannell, L. L., Cragg, G. M., et al. (1991). Novel Alkaloids from the Tropical Plant Ancistrocladus Abbreviatus Inhibit Cell Killing by HIV-1 and HIV-2. J. Med. Chem. 34, 3402-3405. doi:10.1021/jm00116a011

Mei, X., and Wolf, C. (2004). A Highly Congested N,N'-dioxide Fluorosensor for Enantioselective Recognition of Chiral Hydrogen Bond Donors. Chem. Commun., 2004, 2078-2079. doi:10.1039/B407718K

Miyashita, A., Yasuda, A., Takaya, H., Toriumi, K., Ito, T., Souchi, T., et al. (1980). Synthesis of 2,2'-Bis(diphenylphosphino)-1,1'-Binaphthyl (BINAP), an Atropisomeric Chiral Bis(triaryl)phosphine, and its Use in the Rhodium(I)catalyzed Asymmetric Hydrogenation of alpha.-(acylamino)acrylic Acids. J. Am. Chem. Soc. 102, 7932-7934. doi:10.1021/ja00547a020

Moon, L. S., Pal, M., Kasetti, Y., Bharatam, P. V., and Jolly, R. S. (2010). Chiral Solvating Agents for Cyanohydrins and Carboxylic Acids $\dagger$. J. Org. Chem. 75, 5487-5498. doi:10.1021/jo100445d

Mori, K., Ichikawa, Y., Kobayashi, M., Shibata, Y., Yamanaka, M., and Akiyama, T. (2013). Prediction of Suitable Catalyst by 1H NMR: Asymmetric Synthesis of Multisubstituted Biaryls by Chiral Phosphoric Acid Catalyzed Asymmetric Bromination. Chem. Sci. 4, 4235-4239. doi:10.1039/c3sc52142g

Nicolaou, K. C., Boddy, C. N. C., Bräse, S., and Winssinger, N. (1999). Chemistry, Biology, and Medicine of the Glycopeptide Antibiotics. Angew. Chem. Int. Ed. 38, AID-ANIE2096>3.0.CO, 2096-2152. doi:10. 1002/(sici)1521-3773(19990802)38:15<2096:aid-anie2096>3.0.co;2-f

Nieto, S., Lynch, V. M., Anslyn, E. V., Kim, H., and Chin, J. (2008). HighThroughput Screening of Identity, Enantiomeric Excess, and Concentration Using MLCT Transitions in CD Spectroscopy. J. Am. Chem. Soc. 130, 9232-9233. doi:10.1021/ja803443j 
Nieto, S., Dragna, J. M., and Anslyn, E. V. (2010). A Facile Circular Dichroism Protocol for Rapid Determination of Enantiomeric Excess and Concentration of Chiral Primary Amines. Chem. Eur. J. 16, 227-232. doi:10.1002/chem.200902650

Parker, D. (1991). NMR Determination of Enantiomeric Purity. Chem. Rev. 91, 1441-1457. doi:10.1021/cr00007a009

Pham, N. H., and Wenzel, T. J. (2011). A Water-Soluble Calix[4]resorcinarene with a-Methyl-l-prolinylmethyl Groups as a Chiral NMR Solvating Agent. J. Org. Chem. 76, 986-989. doi:10.1021/jo102197w

Pirkle, W. H. (1966). The Nonequivalence of Physical Properties of Enantiomers in Optically Active Solvents. Differences in Nuclear Magnetic Resonance Spectra. I. J. Am. Chem. Soc. 88, 1837. doi:10.1021/ja00960a060

$\mathrm{Pu}$, L. (2004). Fluorescence of Organic Molecules in Chiral Recognition. Chem. Rev. 104, 1687-1716. doi:10.1021/cr030052h

Quinn, T. P., Atwood, P. D., Tanski, J. M., Moore, T. F., and Folmer-Andersen, J. F. (2011). Aza-crown Macrocycles as Chiral Solvating Agents for Mandelic Acid Derivatives. J. Org. Chem. 76, 10020-10030. doi:10.1021/jo2018203

Reetz, M. T., Becker, M. H., Kühling, K. M., and Holzwarth, A. (1998). TimeResolved IR-Thermographic Detection and Screening of Enantioselectivity in Catalytic Reactions. Angew. Chem. Int. Edition 37, 2647-2650. doi:10.1002/ (sici)1521-3773(19981016)37:19<2647:aid-anie2647>3.0.co;2-i

Reetz, M. T., Kühling, K. M., Deege, A., Hinrichs, H., and Belder, D. (2000). SuperHigh-Throughput Screening of Enantioselective Catalysts by Using Capillary Array Electrophoresis. Angew. Chem. Int. Ed. 39, 3891-3893. doi:10.1002/15213773(20001103)39:21\%3C3891:AID-ANIE3891\%3E3.0.CO;2-1

Schurig, V., and Nowotny, H.-P. (1990). Gas Chromatographic Separation of Enantiomers on Cyclodextrin Derivatives. Angew. Chem. Int. Ed. Engl. 29, 939-957. doi:10.1002/anie.199009393

Seco, J. M., Quiñoá, E., and Riguera, R. (2004). The Assignment of Absolute Configuration by NMR†. Chem. Rev. 104, 17-118. doi:10.1021/cr000665j

Tumambac, G. E., and Wolf, C. (2005). Enantioselective Analysis of an Asymmetric Reaction Using a Chiral Fluorosensor. Org. Lett. 7, 4045-4048. doi:10.1021/ol0516216

Wenzel, T. J., and Chisholm, C. D. (2011). Assignment of Absolute Configuration Using Chiral Reagents and NMR Spectroscopy. Chirality 23, 190-214. doi:10. 1002/chir.20889
Wenzel, T. J., and Wilcox, J. D. (2003). Chiral Reagents for the Determination of Enantiomeric Excess and Absolute Configuration Using NMR Spectroscopy. Chirality 15, 256-270. doi:10.1002/chir.10190

Wenzel, T. J. (2007). Discrimination of Chiral Compounds Using NMR. Hoboken, NJ: John Wiley \& Sons.

Wu, C., Liu, H., Li, J., Xiao, H.-P. H.-P., Li, X., and Jiang, J. (2018). Chiral $1 \mathrm{H}$ NMR of Atropisomeric Quinazolinones with Enantiopure Phosphoric Acids. Front. Chem. 6, 300. doi:10.3389/ fchem.2018.00300

Yang, D., Li, X., Fan, Y.-F., and Zhang, D.-W. (2005). Enantioselective Recognition of Carboxylates: A Receptor Derived from a-Aminoxy Acids Functions as a Chiral Shift Reagent for Carboxylic Acids. J. Am. Chem. Soc. 127, 7996-7997. doi:10.1021/ja051072z

Yeh, H. J. C., Balani, S. K., Yagi, H., Greene, R. M. E., Sharma, N. D., Boyd, D. R., et al. (1986). Use of Chiral Lanthanide Shift Reagents in the Determination of Enantiomer Composition and Absolute Configuration of Epoxides and Arene Oxides. J. Org. Chem. 51, 5439-5443. doi:10.1021/ jo00376a080

Zhao, J., Fyles, T. M., and James, T. D. (2004). Chiral Binol-Bisboronic Acid as Fluorescence Sensor for Sugar Acids. Angew. Chem. Int. Ed. 43, 3461-3464. doi:10.1002/anie.200454033

Zhou, Y., Ye, H., and You, L. (2015). Reactivity-based Dynamic Covalent Chemistry: Reversible Binding and Chirality Discrimination of Monoalcohols. J. Org. Chem. 80, 2627-2633. doi:10.1021/jo502801g

Conflict of Interest: The authors declare that the research was conducted in the absence of any commercial or financial relationships that could be construed as a potential conflict of interest.

Copyright (c) 2021 Wan, Jiang and Li. This is an open-access article distributed under the terms of the Creative Commons Attribution License (CC BY). The use, distribution or reproduction in other forums is permitted, provided the original author(s) and the copyright owner(s) are credited and that the original publication in this journal is cited, in accordance with accepted academic practice. No use, distribution or reproduction is permitted which does not comply with these terms. 